\title{
IMPORTANCE OF 18F-FDG-PET/MR IMAGING TO IMPROVE THE ASSESSMENT OF VASCULAR INFLAMMATION IN CHILDHOOD-ONSET TAKAYASU'S ARTERITIS (C-TA) PATIENTS: A MULTICENTER CASE SERIES
}

Gleice Clemente ${ }^{1}$, Renata LF Andrade1, Pedro Henrique Lopes Carneiro ${ }^{1, \star}$, Alexandre W D Souza ${ }^{1}$, Hilton Leão Filho ${ }^{2}$, Fernando M A Coelho'2, Carlos Buchpiguel², Marcos Lima², Camila Carneiro², Rosa Maria Rodrigues Pereira², Nadia Aikawa², Clovis Artur Almeida da Silva², Lucia Maria de Arruda Campos², Gabriel Alves ${ }^{1}$, Camilla Astley², Bruno Gualano², Maria Teresa Terreri ${ }^{1}$

1.Universidade Federal de São Paulo, São Paulo (SP), Brazil.; 2.Universidade de São Paulo, São Paulo (SP), Brazil.

*Corresponding author: pedrohenrique.carneiro@gmail.com

\section{BACKGROUND}

Childhood-onset Takayasu's arteritis (C-TA) is a rare, chronic and relapsing large-vessel vasculitis. There are few validated tools to access c- TA, so, an accurate assessment of arterial wall is mandatory to detect active inflammation and help to guide the immunosuppressive therapy. Hybrid imaging that provides anatomic and metabolic images simultaneously may add data about vascular inflammation. Our aim was to compare patients with both positive PET and MRA versus patients with positive PET and negative MRA, likewise, to compare each arterial segment with both positive PET and MRA versus positive PET and negative MRA.

\section{METHODS}

A three-center cross-sectional study with 17 patients who fulfilled the EULAR/PRINTO/PReS criteria for c-TA was performed 1. The patients underwent 18F-fluordeoxiglucose-positron emission tomography/magnetic resonance (18F-FDG-PET/MR) imaging 2. Positive MRA consisted of arterial wall thickening with contrast-enhancement, whereas positive PET was defined by arterial wall uptake higher than liver degree of FDG uptake. Patients and vessels were allocated into three groups according to the different combinations of imaging findings: group 1 (PET+MRA+), group 2 (PET+MRA-) and group 3 (PET-MRA+).

\section{RESULTS}

PET was positive in 15 (88.2\%) patients and MRA was positive in 10 (58.8\%). Nine patients were from group 1,6 from group 2 and 1 from group 3. Median of metabolic inflammatory volume (MIV) of arterial segments was significantly higher in group 1 compared to group 2 (2346 vs. $1177 \mathrm{~cm} 3$; $p=0.036$ ) (Table1). Fifty-four (19\%) from 284 available arterial segments presented positive findings in one or both images. Positive findings were concordant between PET andMRA in 13\% arterial segments (group1); the remaining 87\% (not concordant) were from group 2 or 3 .

Table 1. Clinical and laboratorial data and PET findings.

\begin{tabular}{cccc}
\hline & $\begin{array}{c}\text { Group 1: } \mathrm{n}=9 \\
(\mathrm{PET}+\mathrm{MRA}+)\end{array}$ & $\begin{array}{c}\text { Group 2: } \mathrm{n}=6 \\
(\text { PET }+ \text { MRA - })\end{array}$ \\
\hline Diagnosis delay, months & $11.0(3.0-27)$ & $20.5(1.6-41.3)$ & 0.595 \\
\hline ESR, mm in 1 ${ }^{\text {st }}$ hour & $8.0(4.5-15.5)$ & $4.5(2.8-13.8)$ & 0.407 \\
\hline CRP, mg/L & $2.7(0.3-15.9)$ & $3.1(1.6-6.3)$ & 0.859 \\
\hline SUVmax & $3.4(3.1-4.3)$ & $3.1(2.5-3.9)$ & 0.272 \\
\hline MIV, cm $^{3}$ & $2346(1438-3304)$ & $1177(869-1880)$ & $0.036^{\star}$ \\
\hline
\end{tabular}

ESR: erythrocyte sedimentation rate; CRP: C reactive protein. Numerical values are presented in median (IQR). * 1 patient had no vessel wall changes in MRA or PET imaging and 1 patient had vessel-wall changes in MRA but no vessel-wall changes in PET.

\section{CONCLUSION}

Our study demonstrated that 18F-FDG-PET/MRI added metabolic information to anatomic image in c-TA patients, and may aid therapeutic decision, especially during immunosuppressive withdrawal.

\section{KEYWORDS}

Takayasu arteritis, Vasculitis, Magnetic resonance imaging. 